\title{
Psychodynamic theories of Schizophrenia - revisited
}

\author{
Karishma Rupani ${ }^{1}$, Avinash De Sousa ${ }^{2}$ \\ ${ }^{1}$ Assistant Professor, Department of Psychiatry, Lokmanya Tilak Municipal Medical College, Mumbai. \\ ${ }^{2}$ Consultant Psychiatrist and Founder Trustee, Desousa Foundation, Mumbai and Research Associate, Department of \\ Psychiatry, Lokmanya Tilak Municipal Medical College, Mumbai. \\ E-mail - avinashdes888@gmail.com
}

\begin{abstract}
There are various theories that have been posited with respect to the development of schizophrenia, Much before the neurobiological and social hypotheses explaining schizophrenia, various psychoanalysts and psychodynamic oriented psychologists had proposed various theories to explain the disorder. The following paper is a review of the various schools of psychodynamics and psychoanalysis that have been used to explain the genesis of schizophrenia. All the theories are revisited and this paper provides the first of its kind collection of the various psychodynamic theories under one roof for the clinician and academic reader alike. This paper is a collection of various psychodynamic theories of schizophrenia over the years and up to the present time. These theories though old have to be viewed in the light of recent advances and clinical relevance to the modern day assessment and management of schizophrenia.
\end{abstract}

Key Words: Schizophrenia, psychodynamic theories, Freud, psychoanalysis.

(Paper received $-8^{\text {th }}$ January 2017, Peer review completed $-4^{\text {th }}$ February 2017, Accepted $-6^{\text {th }}$ March 2017)

\section{INTRODUCTION TO VARIOUS CONCEPTS IN EGO PSYCHOLOGY}

The basic premise of human psychological development is based on adaptation, which involves a reciprocal relationship between the individual and his or her environment. The term 'individual' is restricted not only to the physiological makeup; but also the psychological makeup. What we mean by term 'psychological makeup,' essentially includes the components of the psyche of a particular individual. Here comes in the concept of the 'tripartite model,' or the three basic components of our psyche, which are the 'id,' 'ego,' and 'superego'. The role of the 'id,' is to enable us to act on the pleasure principle. Thus, In the course of normative growth of our brain and body, we progress from requiring immediate and instant gratification of our needs or impulses, to being capable of delaying the gratification of our needs. This is possible due to the tripartite apparatus of our psyche. For illustration, the experience of frustration, in the context of normative growth of brain and body, allow the developing ego to remember experiences long enough to delay gratification and anticipate the future. Part of the power the ego serves to gratify id desires, though not in the immediate and unrestrained terms of the primitive mind. In a reciprocal fashion, the memory of past gratification allows the ego to engage in delayed gratification. This process mandates the creation of an internal world of object representations; and this inner world facilitates further exercise of delayed gratification. As the structures ego and superego mature, the need for external fulfillment diminishes and autonomy increases [1] (Figure 1).

The outcome of successful adaptation or a successful resolution of conflict is a "fitting together" of the individual (id, ego and superego) with the environment. Thus, conflict is neither the cause nor the outcome of psychopathology, but a normal and necessary part of the human condition. It is the unresolved conflict 
between the id, ego and superego that is the cause of psychopathology. Id, ego, and superego continue to develop by the process of differentiation. [2].

Figure 1 - Basic concepts in ego psychology

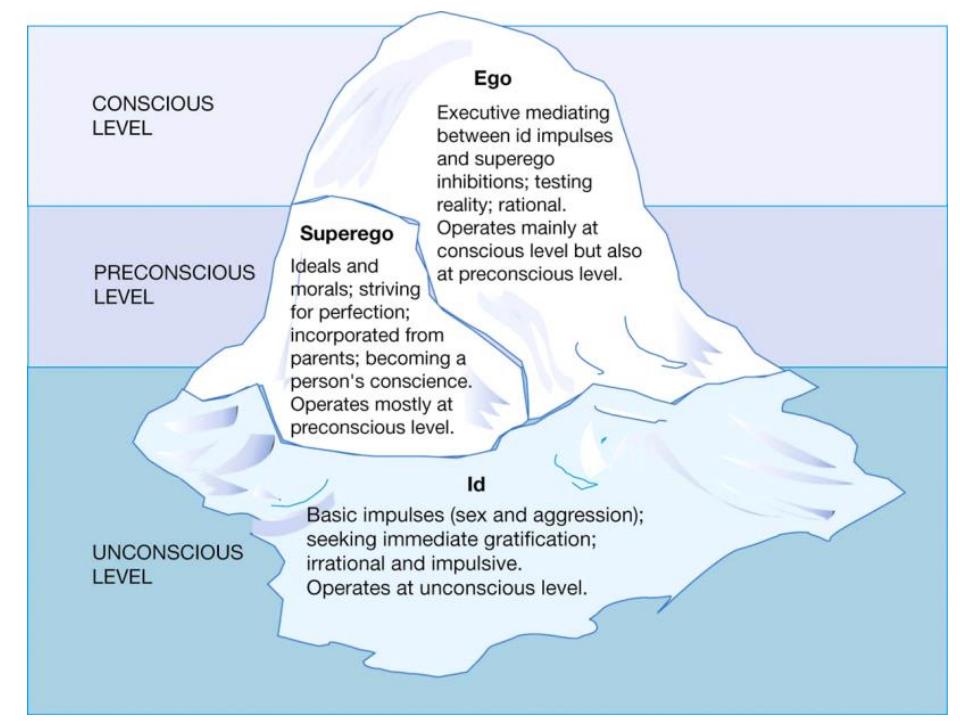

\section{BASIC PREMISES}

The major causes of behavior have their origin in the unconscious. The principle of psychic determinism states that all behavior has a cause/reason and different parts of the unconscious mind are in constant struggle. Our behavior and feelings as adults (including psychological problems) are rooted in our childhood experiences.

According to the psychodynamic approach, abnormality is caused when trauma from unresolved conflict between the id, ego, and superego; the ego is repressed into the unconscious and this causes regression to an earlier stage of the Freudian stages of psychosexual development. In particular, schizophrenia is linked to an early part of the oral stage called primary narcissism during which the ego has not separated from the id. The ego is the rational part of the mind and so the person ceases to operate on the basis of the reality principle, therefore losing touch with reality as the ego is the rational element of the tripartite apparatus. This explains some of the symptoms of schizophrenia [3].

Eugen Bleuler, was the first to use term the word 'schizophrenia' derived from the Greek word for 'split' and 'mind'. In contrast to the popular interpretation of split personality, Bleuler referred to a splitting of the psychic functions. He wrote, "If the disease is marked, the personality loses its unity.... Often ideas are only partially worked out, and fragments of ideas are connected in an illogical way to constitute a new idea. Concepts lose their completeness; seem to dispense with 1 or more of their essential components. Thus, the process of association often works with mere fragments of ideas and concepts. This results in associations which normal individuals will regard as incorrect, bizarre, and utterly unpredictable......In the severest cases emotional and affective expressions seem to be completely lacking...."[4]

\section{CLASSICAL PSYCHOANALYSIS}

\section{SIGMUND FREUD}

\section{Psychoanalytic formulation and the tripartite model of the mind}

The psychodynamic explanation suggests that very harsh childhood experiences result in inner turmoil in the patient giving rise to a conflict between the id, ego and superego (tripartite apparatus). If this conflict 
remains unresolved, it leads to fixation or regression to early stages of psychosexual development. In particular, schizophrenia is linked to an early part of the oral stage called primary narcissism during which the ego had not separated from the id. Due to this the person ceases to operate on the basis of the reality principle [5].

The psychodynamic approach views schizophrenia as the result of the disintegration of the ego. It is the ego's job to keep control of the id's impulses and strike a compromise between the demands of the id and the moral restrictions of the superego. According to Freud, a weak and fragile ego, whose ability to contain the id's desires is limited, can be 'broken apart' by its attempt to contain the id, leaving the id in overall control of the psyche. If this happens, the person loses contact with reality as they can no longer distinguish between themselves and others, their desires and fantasies and reality (which is one of the many functions of the ego). They regress to a state of 'primary narcissism' little different from that of a newborn infant, dominated by their animal instincts, incapable of organizing their own behavior and hallucinating as a result of their basic inability to distinguish between their imaginations and reality [6].

Freud viewed psychotic symptoms as a manifestation of unresolved conflict, the resolution of which results in defective object-relations. He maintained that a delusion is like a patch applied over the tear between the ego and external world which reflects on his viewpoint of symptoms as restitutional, i.e., an attempt to reforge object ties [7].

\section{PAUL FEDERN}

In the late 1920s, Federn published important books such as 'Some Variations in Ego-Feeling' and 'Narcissism in the Structure of the Ego'. In his works he elucidated upon the concepts of 'ego states', 'ego limits', 'ego cathexis' and the median nature of narcissism. Although an ardent supporter of Freud's teachings, Federn's concept of the ego as experience coinciding with 'ego feeling' was inconsistent with Freud's structural approach. Out of loyalty to his mentor, Federn had a tendency to downplay his own theories, even though the conclusions he reached were far different from Freud's [8]

In regards to patients with schizophrenia, he believed that their egos possessed insufficient cathectic energy, and that it was a lack rather than an excess of narcissistic libido that caused a psychotic individuals' difficulties with the object. He also introduced the term mortido to represent Freud's death drive [9].

\section{MARGARET MAHLER}

Margaret Mahler was also a central figure as far as psychoanalysis was concerned. Her main interest was in normal childhood development and how children arrive at the concept of self. Mahler developed the separation-individuation theory of child development. Her work included psychoanalysis with young disturbed children [10].

As per Mahler when there are distortions in the reciprocal relationship between the infant and the mother, the child is unable to separate from, and progress beyond, the closeness and complete dependence that characterizes the mother-child relationship in the oral phase of development. As a result, the person's identity never becomes secure. She attributed the symptomatology of schizophrenia to a derailment of the normal process whereby self-representations (the representation of one's self) and objectrepresentations (the representation of a familiar person) become distinct [11].

\section{HARRY STACK SULLIVAN}

Harry Stack Sullivan viewed schizophrenia as a disturbance in interpersonal relatedness. The patient's massive anxiety creates a sense of unrelatedness that is transformed into parataxic distortions, which are usually, but not always, persecutory. To Sullivan, schizophrenia is an adaptive method used to avoid panic, terror, and disintegration of the sense of self. The source of pathological anxiety results from cumulative experiential traumas during development. Sullivan's work on interpersonal relationships 
became the foundation of interpersonal psychoanalysis, a school of psychoanalytic theory and treatment that stresses the detailed exploration of the nuances of patients' patterns of interacting with others [12].

\section{HEINZ HARTMANN}

Heinz Hartmann (1939/1958) believed the ego included innate capacities that facilitated an individual's ability to adapt to his or her environment. These included perception, attention, memory, concentration, motor coordination, and language. Under normal conditions, what Hartmann called an average expectable environment, these capacities developed into ego functions and had autonomy from the libidinal and aggressive drives; that is, they were not products of frustration and conflict, as Freud (1911) believed [13].

Through Hartmann's focus on ego functions, and how an individual adapts to his or her environment, he worked to create both a general psychology and a clinical instrument with which an analyst could evaluate an individual's functioning and formulate appropriate therapeutic interventions. Based on Hartmann's propositions, the task of the ego psychologist was to neutralize conflicted impulses and expand the conflict-free spheres of ego functions. By doing so, Hartmann believed psychoanalysis facilitated an individual's adaptation to his or her environment [14].

Hartmann powerfully affected the course of psychoanalysis, opening up a crucial investigation of the key processes and vicissitudes of normal development. Hartmann's contributions broadened the scope of psychoanalytic concerns from psychopathology to general human development and from an isolated, selfcontained treatment method to a sweeping intellectual discipline among other disciplines [15].

\section{CLINICAL IMPLICATIONS OF THE PSYCHOANALYTIC THEORY OF SCHIZOPHRENIA}

1. The classical psychoanalysis, which was and still is to some extent, a widely practiced form of treatment of schizophrenia is based on the psychoanalytic theory of schizophrenia.

2. This theory also explains some of the symptomatic manifestations of schizophrenia, and provides an insight into understanding the phenomenology in individual patients and thereby facilitates treatment.

\section{INTERPERSONAL PSYCHOANALYSIS}

Interpersonal psychoanalysis accents the nuances of interpersonal interactions, particularly how individuals protect themselves from anxiety by establishing collusive interactions with others, and the relevance of actual experiences with other persons developmentally (e.g. family and peers) as well as in the present. This is contrasted with the primacy of intrapsychic forces, as in classical psychoanalysis. Interpersonal theory was first introduced by Harry Stack Sullivan and developed further by Frieda FrommReichmann, Clara Thompson, Erich Fromm who contributed to the school of Interpersonal Psychoanalysis.

\section{HARRY STACK SULLIVAN}

Sullivan laid the groundwork for understanding an individual, based on the network of relationships in which he or she is enmeshed. He developed a theory of psychiatry based on interpersonal relationships where cultural forces are largely responsible for mental illnesses. In his words, one must pay attention to the 'interactional', not the 'intrapsychic'. This search for satisfaction via personal involvement with others led Sullivan to characterize loneliness as the most painful of human experiences. He also extended the Freudian psychoanalysis to the treatment of patients with severe mental disorders, particularly schizophrenia [16]. 


\section{FRIEDA FROMM-REICHMANN}

According to her schizophrenia has its root in the failure of the parents - commonly the mother figure - to provide emotional security in infancy. This causes a weak ego organization, inability to give and receive love on an adult level [17].

\section{ERICH FROMM}

Erich Fromm postulated eight basic needs: [18]

1. Relatedness - This includes relationships with others, care, respect, knowledge.

2. Transcendence - Humans have to transcend their nature by destroying or creating people or things. Humans can destroy through malignant aggression, or killing for reasons other than survival, but they can also create and care about their creations.

3. Rootedness - Rootedness is the need to establish roots and to feel at home in the world. Productively, rootedness enables us to grow beyond the security of our mother and establish ties with the outside world. With the nonproductive strategy, we become fixated and afraid to move beyond the security and safety of our mother or a mother substitute.

4. Sense of Identity - The drive for a sense of identity is expressed nonproductively as conformity to a group and productively as individuality.

5. Frame of orientation - Understanding the world and our place in it.

6. Excitation and Stimulation - actively striving for a goal rather than simply responding.

7. Unity - A sense of oneness between one person and the natural and human world outside.

8. Effectiveness - The need to feel accomplished.

\section{CLINICAL IMPLICATIONS OF THE INTERPERSONAL SCHOOL/THEORY OF SCHIZOPHRENIA}

1. Allows us to understand the symptoms of mental illness as arising out of or worsening due to faulty interpersonal interaction.

2. It also gives us an insight into modeling therapeutic techniques based on dynamics of interpersonal interaction namely the interpersonal therapy usedas a treatment modality in schizophrenia.

\section{OBJECT RELATIONS THEORIES}

This theory in psychoanalytic psychology is the process of developing a psyche in relation to others in the environment during childhood. Based on psychodynamic theory, the object relations theory suggests that the way people relate to others and situations in their adult lives are shaped by family experiences during infancy.

\section{MELANIE KLEIN}

Klein believed that both good and bad objects are introjected by the infant, the internalization of good object being essential to the development of healthy ego function. Klein conceptualized the depressive position as "the most mature form of psychological organization", which continues to develop throughout the life span. The depressive position occurs during the second quarter of the first year. Prior to this the infant is in the paranoid-schizoid position, which is characterized by persecutory anxieties and the mechanisms of splitting, projection, introjection, and omnipotence-which includes idealizing and denial - to defend against these anxieties. Depressive and paranoid-schizoid modes of experience continue to intermingle throughout the first few years of childhood [19].

The paranoid-schizoid position is characterized by part object relationships. Part objects are a function of splitting, which takes place in fantasy. At this developmental stage, experience can only be perceived as all 
good or all bad. As part objects, it is the function that is identified by the experiencing self, rather than whole and autonomous others. The hungry infant desires the good breast who feeds it. Should that breast appear, it is the good breast. If the breast does not appear, the hungry and now frustrated infant in its distress has destructive fantasies dominated by oral aggression towards the bad, hallucinated breast. Klein notes that in splitting the object, the ego is also split. The infant who fantasies destruction of the bad breast is not the same infant that takes in the good breast, at least not until obtaining the depressive position, at which point good and bad can be tolerated simultaneously in the same person and the capacity for remorse and reparation ensue. The anxieties of the paranoid schizoid position are of a persecutory nature with fear of the ego's annihilation. Splitting allows good to stay separate from bad. Projection is an attempt to eject the bad in order to control through omnipotent mastery. Splitting is never fully effective, according to Klein, as the ego tends towards integration [20].

\section{WILLIAM FAIRBAIRN}

As per the Fairbairnian Object Relations theory, all interactions between the client and the therapist are occurring in the client's inner object relations world, in one of the three dyads. If the client thinks the therapist is wise and compassionate the therapist sees this as an interaction between the client's Libidinal Ego and Exciting Object. If the client is angry at the therapist for not meeting the client's needs, the therapist might see it as an interaction between the client's Antilibinal Ego and the Bad Object. The therapist might ask the client if this particular interaction reminds the client of something from childhood [21].

Fairbairn posited six ego positions or inner voices, or 3 pairs [22]

- The Whole Ego relating to the Good Object, is the healthy inner child relating to and nurturing inner parent. This is the part of the inner world that object relations therapists try to expand and grow.

- The Antilibidinal Ego relating to the Bad Object, is the depressed, angry or hopeless inner child relating to the rejecting or neglectful inner parent. Whenever someone speaks in a tantrum-like way they are speaking from the Antilibidinal Ego, and they are speaking to the Bad Object. Whenever someone is overly critical and harshly judgmental they are speaking from the Bad Object part of their personality, and are speaking to the Antilibidinal Ego (hopeless inner child).

- The Libidinal Ego relating to the Exciting Object, is the gullible and overly hopeful inner child relating to the exciting over-promising inner parent. Whenever a person goes back to their cheating or abusive spouse they are operating from their Libidinal Ego and relating to the Exciting Object in their inner worlds. Whenever they are in an addiction they are treating whatever they are addicted to as if it were an Exciting Object.

\section{DONALD WINNICOTT}

He considered the key role of the 'good enough' mother as adaptation to the baby, thus giving it a sense of control, 'omnipotence' and the comfort of being connected with the mother. This 'holding environment' allows the infant to transition at its own rate to a more autonomous position.

The three key aspects of the environment identified are holding, handling and object-presenting. The mother may thus hold the child, handle it and present objects to it, whether it is herself, her breast or a separate object. The good enough mother will do this to the general satisfaction of the child. However if the child perceives that his needs are thwarted, that may lead to disintegration of the ego [23].

\section{EDITH JACOBSON}

Edith Jacobson was a German psychoanalyst. Her major contributions to psychoanalytic thinking dealt with the development of the sense of identity and self-esteem and with an understanding of depression and psychosis. She was able to integrate the tripartite structural model of classic psychoanalysis with 
the theory of object relations into a revised drive theory. Thereby, she increased the treatment possibilities of the more disturbed pre-oedipal patients [24].

\section{CLINICAL IMPLICATIONS OF THE OBJECT RELATIONS THEORIES}

1. This theory laid emphasis on the repercussions that childhood events had on the development of the sense of self and subsequent behavior patterns

2. It formed the basis of child psychoanalysis and led to the evolution of 'Play Therapy' which is a form of psychoanalysis in children.

\section{FAMILY TRANSACTON MODELS THEORY}

\section{DOUBLE BIND THEORY}

Double bind theory was first described by Gregory Bateson and Donald Jackson in 1950s. The essential hypothesis of the double bind theory is that the 'victim' - the person who becomes unwell-finds him or herself in a communicational matrix, in which messages contradict each other, the contradiction is not able to be communicated on and the unwell person is not able to leave the field of interaction [25].

It can be described as an emotionally distressing dilemma in communication in which an individual (or group) receives two or more conflicting messages, and one message negates the other. This creates a situation in which a successful response to one message results in a failed response to the other (and vice versa), so that the person will automatically be wrong regardless of response. The double bind occurs when the person cannot confront the inherent dilemma, and therefore can neither resolve it nor opt out of the situation [26].

Double binds are often utilized as a form of control without open coercion - the use of confusion makes them both difficult to respond to as well as to resist. In the long run this manifests itself as schizophrenic symptoms, e.g. flattened effect, delusions, hallucinations, incoherent thinking and speaking and in some cases, paranoia.

\section{MARITAL SCHISM AND SKEWED FAMILIES}

Theodore Lidz described two abnormal patterns of family behavior. In one family type, with a prominent schism between the parents, one parent is overly close to a child of the opposite gender. In the other family type, a skewed relationship between a child and one parent involves a power struggle between the parents and the resulting dominance of one parent. These dynamics stress the tenuous adaptive capacity of the schizophrenic person [27].

\section{PSEUDO-MUTUALITY AND PSEUDO-HOSTILITY}

Communication deviance (CD) occurs when a speaker fails to effectively communicate meaning to their listener with confusing speech or illogical speech patterns. These disturbances can range from vague linguistic references, contradictory statements to more encompassing non-verbal problems. The term was originally introduced by Wynne and Singer in 1963 to describe a communication style found among parents who had children with schizophrenia. A recent meta-analysis reported that communication deviance is highly prevalent in parents of patients diagnosed with schizophrenia and adoption studies have reported significant associations between $\mathrm{CD}$ in the parent and thought disorder in the offspring, however, the mechanisms by which CD impacts on the offspring's cognition are still unknown [28].

The research of psychiatrists and psychoanalysts Lyman Wynne and Theodore Lidz on communication deviance and roles (e.g., pseudo-mutuality, pseudo-hostility, schism and skew) in families of people with schizophrenia also became influential with systems-communications oriented theorists and therapists [29]. 


\section{CLINICAL IMPLICATIONS OF THE FAMILY TRANSACTION MODEL}

1. This laid emphasis on the family dynamic underpinnings that led to deviant thought and behavior patterns.

2. This theory is utilized by clinically translating it in 'family therapy'.

\section{GOALS OF PSYCHODYNAMIC PSYCHOTHERAPY IN SCHIZOPHRENIA}

1. Psychodynamic psychotherapy focuses on affect and expression of emotion. Exploration and discussion of the full range of a patient's emotions is encouraged. The therapist helps the patient describe and put words to feelings, including those that are contradictory, troubling or threatening. It facilitates resurgence of feelings that the patient may not initially be able to recognize or acknowledge

2. Exploration of attempts to avoid distressing thoughts and feelings. This avoidance (in theoretical terms, defense and resistance), which manifests itself in subtle forms, such as missing sessions or being evasive. Psychodynamic therapists actively focus on and explore avoidances.

3. Identification of recurring themes and patterns. Psychodynamic therapists work to identify and explore recurring themes and patterns in patients' thoughts, feelings, self-concept, relationships, and life experiences.

4. Discussion of past experience (developmental focus). Psychodynamic therapists explore early experiences, the relation between past and present, with the goal to help patients free themselves from the burden and focus on the here and now.

5. Focus on interpersonal relations. Psychodynamic therapy places heavy emphasis on patients' relationships and interpersonal experience (in theoretical terms, object relations and attachment). Both adaptive and non adaptive aspects of personality and self-concept are identified.

6. Focus on the therapy relationship. The relationship between therapist and patient is itself an important interpersonal relationship, one that can become deeply meaningful. Repetitive themes in a person's relationships tend to emerge in some form in the therapy relationship. The recurrence of interpersonal themes in the therapy relationship (in theoretical terms, transference and counter transference) is used to explore and rework them in vivo with the goal of increasing flexibility in interpersonal relationships.

7. Exploration of fantasy life. In contrast to other therapies in which the therapist may actively structure sessions or follow a predetermined agenda, psychodynamic therapy uses exploration of fantasy life as an access to the patient's suppressed thoughts.

8. Psychodynamic therapy encourages patients to speak freely about whatever is on their minds. When patients do this, their thoughts naturally range over many areas of mental life, including desires, fears, fantasies and dreams, which in many cases the patient has not previously attempted to put into words.

The goals of psychodynamic therapy include, but extend beyond, symptom remission. Successful treatment should not only relieve symptoms, but also foster the positive presence of psychological capacities and resources. Depending on the person and the circumstances, these might include the capacity to have more fulfilling relationships, make more effective use of one's talents and abilities, tolerate a wider range of affect and face life's challenges with greater freedom and flexibility. Such ends are pursued through a process of self-reflection, self-exploration, and self-discovery that takes place in the context of a safe and deeply authentic relationship between therapist and patient. [30].

From a modern perspective, to validate the therapeutic effects of psychodynamic psychotherapy, research in terms of meta-analyses has been done. A meta-analysis including 17 high-quality randomized controlled trials of psychodynamic therapy was done, which reported an effect size of 1.17 for psychodynamic therapy compared with controls [31]. 
The pre-treatment to post-treatment effect size was1.39, which increased to 1.57 at long-term follow-up, which occurred an average of 13 months post treatment. Translating these effect sizes into percentage terms, the authors noted that patients treated with psychodynamic therapy were "better off with regard to their target problems than $92 \%$ of the patients before therapy" [31]. The consistent trend toward larger effect sizes at follow-up suggests that psychodynamic therapy sets in motion psychological processes that lead to ongoing change, even after therapy has ended. There are also far reaching implications in the group therapy and psychoeducation of patients and family members with schizophrenia.

\section{LIMITATIONS}

The empirical literature on psychodynamic treatments does, however, have important limitations. First, the number of randomized controlled trials for other forms of psychotherapy, notably CBT, is considerably larger than that for psychodynamic therapy, perhaps by an order of magnitude. In too many cases, characteristics of patient samples have been too loosely specified, treatment methods have been inadequately specified and monitored, and control conditions have not been optimal [32].

\section{REFERENCES}

1. Blanck G, Blanck R. Ego psychology: Theory and practice. Columbia University Press; 1994.

2. Goldstein EG. Ego psychology and social work practice. Simon and Schuster; 1995.

3. Berzoff J, Flanagan LM, Hertz P. Inside out and outside in: Psychodynamic clinical theory and psychopathology in contemporary multicultural contexts. Jason Aronson; 2008.

4. Bleuler E. La Schizophrenie. Rapport au Congres des medecins alienistes et neurologistes de France et des pays de langue francaise. [Schizophrenia. Report to the Congress of French and French-speaking alienists and neurologists], 30th session. Geneva, Lausanne, Paris, France: Masson; 1926.

5. Kline P. Fact and Fantasy in Freudian Theory (RLE: Freud). Routledge; 2013.

6. Frosh S. The politics of psychoanalysis: An introduction to Freudian and post-Freudian theory. Macmillan education; 1987.

7. Freud S. Introductory lectures on psychoanalysis. WW Norton \& Company; 1977.

8. Federn P. Principles of psychotherapy in latent schizophrenia. Am J Psychotherapy 1947;1(2):129-44.

9. Federn P. Psychoanalysis of psychoses. Psychiatr Quart 1963;17(1):3-19.

10. Mahler MS, Pine F, Bergman A. The psychological birth of the human infant: Symbiosis and individuation. Basic Books; 2008.

11. Mahler MS. On sadness and grief in infancy and childhood-Loss and restoration of the symbiotic love object. Psychoanalytic Study of the Child 1961;16:332-51.

12. Sullivan HS. The interpersonal theory of psychiatry. Routledge; 2013.

13. Hartmann H. Essays on ego psychology: Selected problems in psychoanalytic theory. Intl Universities $\operatorname{Pr}$ Inc; 1964.

14. Hartmann H. The development of the ego concept in Freud's work. The International journal of psychoanalysis. 1956;37:425.

15. Hartmann H. Ego Psychology and the Problem of Adaptation. New York: International University Press ; 1958.

16. Evans III FB. Harry Stack Sullivan: interpersonal theory and psychotherapy. Routledge; 2006.

17. Fromm-Reichmann F. Principles of intensive psychotherapy. University of Chicago Press; 1960.

18. Fromm E. Man for himself: An inquiry into the psychology of ethics. Routledge; 2013.

19. Klein M, Strachey A. The psycho-analysis of children. Random House; 1997.

20. Klein M. Some theoretical conclusions regarding the emotional life of the infant. The Writings of Melanie Klein. 1952;3:61-93.

21. Fairbairn WR. Psychoanalytic studies of the personality. Psychology Press; 1994.

22. Fairbairn WR. From instinct to self: Selected papers of WRD Fairbairn. Birtles EF, Scharff DE, editors. J. Aronson; 1994.

23. Winnicott DW. The maturational process and the facilitating environment. Hogarth Press : London ; 1965.

24. Jacobson E. Psychotic conflict and reality. Intl Universities Pr Inc; 1967.

25. Watzlawick P. A review of the double bind theory. Family Process. 1963 Mar 1;2(1):132-53. 
26. Gibney P. The double bind theory: Still crazy-making after all these years. Psychotherapy in Australia. 2006 May;12(3):48.

27. Lidz T. The origin and treatment of schizophrenic disorders. Basic Books; 1973.

28. Wynne L, Ryckoff I, Day J, Hirsch S. Pseudomutuality in the family relations. Family Processes and Schizophrenia. 1958:157-63.

29. Wynne LC. Pseudo-Mutuality in the Family Relations of Schizophrenics, G. Handel (ed.),'The Psychosocial Interior of the Family'. London: Allen ; 1968.

30. Leichsenring F, Rabung S. Effectiveness of long-term psychodynamic psychotherapy: A meta-analysis. JAMA 2008;300(13):1551-65.

31. Leichsenring F, Rabung S, Leibing E. The efficacy of short-term psychodynamic psychotherapy in specific psychiatric disorders: A meta-analysis. Arch Gen Psychiatry 2004;61:1208-16.

32. Lambert MJ, Ogles BM. The efficacy and effectiveness of psychotherapy. In M. Lambert (Ed.), Bergin and Garfield's handbook of psychotherapy and behavior change (5th ed., pp. 139-193). New York, NY: Wiley ; 2004.

Acknowledgements - Nil

Source of Funding - Nil

Conflict of Interest - Nil 